\title{
Medicina sob as lentes da História: reflexões teórico-metodológicas
}

\author{
Medicine under the lens of history: \\ theoretical and methodological reflections
}

André Mota ${ }^{1}$

Lilia Blima Schraiber ${ }^{1}$
${ }^{1}$ Departamento de Medicina Preventiva, Faculdade de Medicina, Universidade de São Paulo. Av. Dr. Arnaldo Vieira de Carvalho 455/4\%, Cerqueira Cesar. 01.246903 São Paulo SP Brasil. amota@museu.fm.usp.br

\begin{abstract}
The need for studies in the field of health to be based on a historical perspective has opened up new horizons for the analysis of the conditions for the creation of a body of knowledge aimed at explaining the role of social elements in determining pathological processes and health practices. The purpose of this paper is to examine how historical science, with its methodological aspects of analysis, has contributed to the physician's practice, especially raising broader critical aspects of the issues related to the field of health care. It is based on dialogues between culture and society molded around a discursive order to act not just as a language, but in its effective implementation within a medical rationale, with attention to the ruptures and continuities of a scientific discourse. Key words History, Medical practice, Health care, Corporality
\end{abstract}

Resumo A necessidade de se pautarem estudos do campo da saúde numa perspectiva histórica originou novos horizontes analíticos para as condições de emergência de saberes voltados à explicação do social na determinação de processos patológicos e das práticas de saúde. O propósito deste texto é considerar como a ciência histórica, em seus aspectos metodológicos de análise, tem concorrido para a prática do médico, levantando particularmente aspectos críticos mais amplos das questões atinentes ao campo do Cuidado em Saúde, a partir de diálogos entre cultura e a sociedade, plasmados por uma ordem discursiva em ato, não apenas no fazer-se enquanto linguagem, mas na sua efetivação prática dentro de uma racionalidade médica, com a atenção às rupturas e permanências de um discurso científico.

Palavras-chave História, Prática médica, Cuidado em saúde, Corporalidade 


\section{Introdução}

A necessidade de se pautarem estudos do campo da saúde numa perspectiva histórica originou novos horizontes analíticos para as condições de emergência de saberes voltados à explicação do social na determinação de processos patológicos e das práticas de saúde ${ }^{1}$. No caso da história da medicina e da saúde pública, diversos trabalhos puderam se aproximar e reiterar a compreensão da organização das instituições médicas, da história das doenças e das tecnologias empregadas em políticas em saúde e na chamada "medicina popular". Dentro desse quadro, a história está apta a compreender contextual e sociologicamente as políticas e as práticas de saúde, confrontando novos temas, metodologias, problemas e alternativas que requalifiquem suas interpretações, conforme bem apontam pesquisadores brasileiros estudiosos do campo da História e da Sociologia das práticas médicas e de saúde².

Muito embora se possam recuperar tais contribuições não é este o propósito do presente texto. Assim, não será feita uma revisão da produção, já abundante no país e internacionalmente, acerca da literatura que trata da História da Medicina, da Saúde Pública e da História da Saúde Coletiva brasileira. Nosso propósito é de natureza diversa, respondendo a um convite à reflexão metodológica no que tange a possíveis contribuições da História como disciplina das Ciências Humanas para a compreensão de questões do campo da Saúde. Sob tal instigação, o presente texto pretende dialogar com outras disciplinas que, na Saúde e, sobretudo, na Saúde Coletiva, exploram, também em sua historicidade, questões do social e do humano, tais como, a Sociologia e a Antropologia.

Nesse sentido, buscaremos no presente texto apontar no que as contribuições da História são particulares, também se valendo da contextualização social da Medicina e da Saúde Pública no exame das questões humanas da vida em sociedade. A particularidade residirá não só nas questões que elege como abordagem científica, mas nos princípios metodológicos que opera. Por isso, pretendemos mostrar que a História tomará a cultura e a sociedade de modo diverso e, em certo sentido, complementar ao modo como aquelas disciplinas o fazem. Para tal, elegemos aqui um recorte do campo da Saúde que constitui uma relevante problemática contemporânea. Trata-se da questão do cuidado, examinada sob a perspectiva da História, isto é, apontando o caráter histórico de uma questão contemporâ- nea, desse modo centrando nossa preocupação no âmbito das práticas profissionais e, nestas, enfocando especificamente a prática médica. Assim sendo, buscamos contribuir com a discussão sobre a complexidade que cerca a aplicação das Ciências Humanas e Sociais ao campo da Saúde quando se almeja um diálogo com pesquisadores e profissionais desse campo, em particular com os médicos.

Antes, porém, para deixar ainda mais claro as contribuições da presente reflexão, é importante sinalizar que, sendo teórico-metodológica, nossa abordagem do cuidado não se identificará ao estudo histórico, ou ao estudo historiográfico ou àquele memorialista, cabendo apontar as distinções entre eles. Se o primeiro tipo de estudo em História busca identificar, datando e contextualizando socialmente, acontecimentos que cercam origens e progressivas modificações da questão que se estuda, provendo uma leitura interpretativa - entre diversas possíveis - do passado ao contemporâneo, a Historiografia resgata esse leque de leituras, examinando a gama da produção histórica em torno à questão que se estuda. Em ambos os casos, o exame dos princípios metodológicos que cercam cada leitura pode ser feito, mas não é necessário ou tampouco o centro do estudo, o que seria o caso de estudos voltados à Epistemologia Histórica, que então, como no presente texto, são reflexões voltadas exatamente para o exame da abordagem teórico-metodológica que a História fará. Já a vertente memorialista em História, e a qual, por razões de confundimento metodológico, iremos tratar mais detidamente adiante neste texto, preocupa-se em registrar os vestígios dos acontecimentos como sinais que permitem se aproximar do passado e cuja leitura ou interpretação se resume ao conhecimento desses sinais, dos vestígios em si mesmos.

Isto posto, podemos dizer que não faremos uma história do cuidado em saúde, tampouco sua historiografia, revisando a produção dessa história. O que antes faremos será apontar de que modo o uso de referenciais metodológicos determinados, tais como a 'ruptura', a 'permanência', a adoção de 'tempos de distintas acelerações' e a 'circularidade social' de questões relativas ao cuidado, desde suas origens, aqui datadas na Modernidade, à contemporaneidade, oferecem possibilidades específicas e próprias à História de interpretação e compreensão da cultura e da sociedade quanto ao modo de ser da prática profissional dos médicos.

Por isso, abordaremos, de um lado, o objeto da prática médica, na dicotomia 'o corpo - o 
doente', e abordaremos, de outro, a finalidade de sua intervenção traduzida em produto dessa prática, na dicotomia 'a cura/controle - o cuidado', que são aspectos fulcrais, da perspectiva das ciências humanas e sociais, para o exame da prática em Medicina.

Buscaremos apontar desconstruções conceituais que a História pode imprimir no estudo da prática médica. Uma delas refere-se à soberania do conhecimento técnico-científico na configuração material e na qualificação de sentidos da prática dos médicos; outra, à redução biomédica dos adoecimentos na aproximação dos doentes, sendo, ambas, a forma tal como os próprios médicos abordam suas práticas e os adoecimentos. Examinando como a História, de modo próprio a este campo disciplinar, considera as rupturas e as permanências, por meio de leituras sempre abertas de rastros e vestígios do passado na compreensão do presente, queremos evidenciar que essa forma metodológica não apenas gera um olhar diverso daquele dos médicos quanto à historicidade e à socialidade da prática médica, quanto permite a compreensão de circularidades materiais e simbólicas que ocorrem socialmente entre aspectos tradicionais e aspectos completamente novos dessa prática, sempre, historicamente, em transformação.

Por isso, apoiando-nos em tempos de distintas acelerações para examinar rupturas e permanências, em circularidade social, vamos apontar algumas ampliações interpretativo-compreensivas que a História nos faculta por referência a essa prática, e que podem ser significativas também ao campo da Saúde.

\section{História e Memória: distintas contribuições}

Já pelo fato de haver, sobretudo na Medicina, uma prática memorialista, com a criação de diversos acervos de equipamentos e documentos, assim como, certa indistinção conceitual sobre o que é da Memória e o que é da História, vamos apontar, ainda que em primeiras aproximações, sua diferenças e convergências.

A renúncia a uma temporalidade histórica linear em favor de uma temporalidade de múltiplos tempos, como nos ensinou Braudel ${ }^{3}$, é uma das questões centrais para compreender o passado dos homens e da memória constituída em torno deles. A memória é um material sempre importante e não dissociado do saber histórico, já que não há história que deixe marcas apenas naquilo que é visível e que está sob a luz da razão e do registro oficial de um passado, afinal, nem todos os documentos são testemunhos [...] nem todos os fatos considerados estabelecidos são acontecimentos pontuais. Muitos acontecimentos reputados históricos nunca foram lembranças de ninguém. O ato concreto pelo qual reaprendemos o passado no presente é o reconhecimento ${ }^{4}$.

No caso da Medicina, essa distinção nos faz prezar o que é da memória, que são os vestígios mais visíveis ou facilmente presentes sob uma determinada narrativa, quase sempre corporativa sobre seu saber e prática. É o caso de textos que sobrevivem, tal como tratados sobre doenças, vultos da Medicina, relatos de adoecimentos em certos contextos e épocas ou os artefatos e os instrumentos da prática dos médicos que podem ser coletados. Não obstante, para a história a memória traduzida pela documentação será um de seus polos construtores de sua ciência, envolvendo outras esferas constitutivas como a teoria e a produção historiográfica, podendo por isso nos levar em busca dos sentidos que esses representantes da memória podem revelar por uma interpretação que damos a determinados conjuntos deles, de modo que formem um todo compreensível, mesmo que limitado às evidências, acerca da Medicina do passado marcando suas distinções com o presente para que possamos também compreendê-lo e atualizá-lo.

Nesse sentido, o que procuramos aqui compreender do presente, quanto aos fins da prática médica é o cuidado, tema crítico de extrema atualidade. Ou, se pensarmos as rupturas da contemporaneidade, trata-se ao menos de compreender a passagem da prática voltada para a cura dos doentes àquela voltada para o cuidado dos doentes.

Se, de um lado, o envelhecimento populacional, em reconhecida transição demográfica e epidemiológica, tensiona as práticas de cura na direção do desenvolvimento de cuidados, ante a perspectiva dos adoecimentos crônicos, de outro lado, o reconhecimento dos direitos sociais e humanos também amplia essa tensão sobre uma prática que, na ótica de um tempo de longa duração, há muito se encontra ancorada no poder unilateral de um de seus sujeitos: o médico. Este reconhecimento dos direitos sociais e humanos, sem dúvi$\mathrm{da}$, vem promovendo rupturas na tradicional autoridade médica, questionamentos sociais de que, ainda hoje, se ressentem os médicos.

Tal aproximação da prática médica implicará nova aproximação também de seu objeto: o corpo doente é o corpo que cobra e é cobrado. E justamente suas formas não silenciadas e refletidas pelo sofrimento têm sua historicidade num 
tempo nem sempre compreendido. Nesse sentido, quando falamos em cuidado, entendemos que existe aí uma responsabilidade: cuidar é tornar-se responsável pela articulação entre o sofrimento e o homem, na busca de preservar do sofrimento a potencialidade dessa pessoa como sujeito histórico, mesmo que sua experiência corporal dê sinais de que um acontecimento (o adoecer) lhe roubou essa esperança de permanência numa linha progressiva e estável da vida humana.

Adicionalmente, essa perspectiva de centrarmos nossas considerações no plano do cuidado também nos leva a fazer uma segunda distinção importante em termos da disciplina da História: quando se toma como objeto o conhecimento científico ou o âmbito das práticas. Aqui, estamos no segundo caso, já buscando desconstruir a noção de que as práticas poderão ser estudadas e compreendidas tão somente pela pesquisa sobre o conhecimento ou o saber em Medicina, como a seguir apontaremos.

\section{Das rupturas históricas na prática médica:} o cuidado como questão

Em uma primeira aproximação não há como deixar de ponderar o quanto já há de ruptura quando contemporaneamente passamos a tematizar o cuidado, em contraste com as denominações anteriores dadas ao produto da intervenção médica: na modernidade, a medicina começa ligando-se ao curar ou ao tratar, pois, como aponta Foucault ${ }^{5}$, seu nascimento moderno está vinculado à transformação do hospital em "instrumento de cura", ou nas palavras de $\mathrm{Luz}^{6}$, a medicina se vê como teoria e arte de curar.

Assim, remeter a prática médica ao cuidado que se produz nas intervenções assistenciais significa um deslocamento do olhar quanto à finalidade da intervenção, antes focalizado na cura ou, no máximo, no controle, com o advento, já na metade do século XX, do saber preventivista e do crescimento das doenças crônicas. Tal deslocamento traz para o primeiro plano, mais que o produto, o próprio processo dessa intervenção: o encontro clínico.

Podemos nos perguntar o que significa esse deslocamento ou de que modo o cuidar passou a ser uma referência para a prática médica? A resposta deve ser buscada na situação atual da medicina, que permite postulá-la como prática "desumanizada”. Ainda que caibam questões sobre tal designação, é forçoso admitir que ela remete ao recente e importante movimento social de reforma médica: o movimento pela humanização da medicina. Liga-se este ao diagnóstico do tecnicismo que permeia a prática médica atual, produto do progressivo afastamento da medicina como ciência das doenças daquela concebida como arte de curar, em que a teoria sobre os adoecimentos servia à $\operatorname{arte}^{7,8}$.

Em que pesem os vestígios dessa possibilidade quando, conformando-se como prática da modernidade, a medicina já passa a centrar a sua num saber progressivamente mais abstraído das condições vividas dos adoecimentos - o que tem sido apontado pelo deslocamento de seu interesse dos doentes para as doenças -, é só com o desenvolvimento daquela tecnologia que pode intervir em grande escala no corpo dos doentes que se mostrará visível o conflito entre o caráter científico e o caráter pragmático da prática médica, quando resolver problemas passa a ser substituído por aplicar a ciência ${ }^{8}$. É precisamente essa substituição que está sub judice quando se adota a perspectiva do cuidado.

O termo cuidado designa para nós uma forma específica de atuar no encontro clínico, isto é, um determinado modo de construção e desenvolvimento da relação entre o médico e seu paciente $^{1}$. À primeira vista, podemos dizer que a relação médico-paciente diz respeito à necessidade que tem esse profissional de fazer um diagnóstico e de elaborar uma terapêutica correspondente, para fazer frente aos motivos pelos quais o paciente recorreu a ele. Quando o paciente procura o médico, leva suas queixas e demandas por cuidado com base em suas necessidades pessoais de reparação ou prevenção de adoecimentos. Nesse caso, a relação seria a melhor forma de fazer a anamnese, o exame clínico e os exames complementares diagnósticos, em conformidade com o conhecimento cientifico disponível, para alcançar um tratamento adequado nesse mesmo plano cientifico. A essa dinâmica de relação podemos chamar de técnica, porque voltada para a aplicação dos conhecimentos científicos à assistência que se presta. Ao acerto na recuperação do doente ou na prevenção do adoecimento assim conquistado chamamos de êxito técnico. Cuidar, então, diz respeito ao êxito técnico, voltado, como dito, para a pronta reparação do corpo orgânico.

Mas a proposta terapêutica também deve ter sentido para o paciente e ser factível dentro de suas condições usuais de vida como um sujeito da sociedade e, pois, como trabalhador, membro de uma família, vivendo em determinado contexto, urbano ou rural, desfrutando de determinadas práticas de lazer etc. Isso equivale a dizer que o êxito técnico deve incluir a possibili- 
dade de um outro no modo de vida do paciente e também ser condizente com suas expectativas futuras e valores de novas realizações.

De um lado, essa condição depende profundamente da própria sabedoria do paciente para lidar com seus adoecimentos: o saber prático dos enfermos ou as competências práticas das pessoas para lidar com obstáculos à vida que elas percebem em seu cotidiano 9 . De outro, suas crenças e expectativas dizem respeito a projetos de vida que visam melhorá-la e, assim, configuram o que se pode chamar de projeto de felicidade. Uma proposta terapêutica que contemple esse projeto e se enquadre bem nas questões de vida cotidiana dos pacientes não será rejeitada por eles e representará um êxito, agora denominado prático, diante das contingências de sua situação específica e particular ${ }^{1}$.

Do ponto de vista do profissional, para construir tal proposta e exatamente naquele momento da aplicação do conhecimento científico à sua prática técnica, ele terá que operar uma importante reflexão crítica acerca do êxito técnico, no sentido de atentar para o melhor modo de combiná-lo com o êxito prático ${ }^{8,10}$. Isso em geral exige adaptar a formulação científica submetendo a aplicação do conhecimento a uma sabedoria que advém de sua própria experiência clínica - desta feita, um saber prático do próprio profissional ${ }^{7}$.

Assim, o conceito de cuidado que adotamos engloba essas duas construções do médico no encontro clínico: a do êxito técnico e a do êxito prático, este último referido por Ayres como sucesso prático $^{1}$. A relação com o paciente, pois, será a que busca essas duas construções, simultaneamente, ao produzir a relação de caráter técnicocientífico e de caráter interativo entre o médico e o paciente, no encontro clínico. É sob essa perspectiva de cuidado e de encontro clínico que examinaremos quais são as possíveis contribuições da História.

\section{Historicidade dos fins e algumas permanências dos meios: a releitura da prática médica como prática social}

Comecemos pela afirmação de que, além de técnica, a prática médica é também social ${ }^{7,11,12}$, embora esse caráter não fique claro para os profissionais. Isso não quer dizer que, como agentes dessa prática, os médicos não contribuam com seu desempenho para reproduzir a vida social, mas que o fazem sem reconhecer esse caráter social no exercício de suas ações. Assim, no âmbito de sua ação técnica, esses profissionais se encontram alienados de sua condição de agentes do próprio social.

Donnangelo identifica esse não reconhecimento pelos médicos com o caráter de neutralidade de que se reveste a prática em medicina, o que se estende às demais práticas técnicas da sociedade, dentre as quais podemos incluir as de saúde de modo geral, marcadas que são pela própria medicina. Em suas palavras, diferentemente de outras práticas sociais, cuja origem é coincidente com a própria emergência ou com o desenvolvimento da sociedade capitalista, a medicina tende a revestir-se mais facilmente de um caráter de neutralidade face às determinações específicas que adquire na sociedade de classes. [...] Tal concepção, que se elabora e reelabora, também por referência às demais práticas técnicas, no conjunto das relações sociais próprias a essa sociedade, encontra, ainda, na marcada continuidade histórica da medicina um de seus principais suportes. A prática médica e seus agentes não foram instituídos no interior do modo de produção capitalista ${ }^{11}$.

De outro lado, a autora também chama atenção para o fato de que, por não ter sido criada com o capitalismo - embora nele tenha adquirido sentidos e procedimentos completamente outros, por referência a diferentes modos de produção e estruturação do social - e por sua qualidade de ação de ciência, produz-se para a prática médica uma espécie de continuidade histórica e, por isso mesmo, não apenas uma neutralidade por referência ao social, mas uma constância histórica de suas finalidades como prática. Na mesma obra, ela menciona o texto de Cont ${ }^{13}$, para quem a medicina é vista como prática comprometida apenas com o ideal altruísta de curar, interessando-se, portanto, tão somente pelo desenvolvimento contínuo de seus meios. Assim se explicariam as inovações técnicas e tecnológicas - sempre na perspectiva do "bem curar". Nesse sentido, Conti ${ }^{13}$ revela que a visão hegemônica é de que a historicidade da prática médica se restringe apenas a seus meios, sendo suas finalidades imutáveis, numa espécie de "a-historicidade" de seus fins.

É por essa razão que a própria Donnangelo também dirá: A medicina, que em uma primeira aproximação pode ser encarada como prática técnica, isto é, como manipulação de um conjunto de instrumentos técnicos e científicos para produzir uma ação transformadora sobre determinados objetos - o corpo, o meio físico -, responde enquanto tal a exigências que se definem à margem da própria técnica, no todo organizado das práticas sociais determinadas, econômicas, politicas e ideoló- 
gicas entre as quais se inclui. Tais exigências regulam não apenas a presença da própria prática, mas participam também do dimensionamento do objeto ao qual se aplica, dos meios de trabalho que ela opera, da forma e destinação de seus produtos. Essa articulação da medicina com as demais práticas sociais constitui o ponto estratégico do qual melhor se pode apreender o seu caráter histórico ${ }^{11}$.

Com base nessas afirmações, observa-se que, do ponto de vista ideológico e reforçando-se na circularidade dos argumentos, os profissionais da saúde se abstraem da socialidade de suas práticas, postulando-as como neutras quanto aos valores que regem sua ação. Tal abstração está baseada na ausência de percepção de seu sentido histórico como prática e não apenas como uso de tecnologias ou instrumentos disponíveis, isto é, uma ausência de percepção de que o próprio uso das tecnologias é maior ou menor, e muda, ora mais, ora menos, em determinadas direções, a depender dos objetivos sociais que esse uso de tecnologias pretenda atingir, na reparação dos adoecimentos.

Tomada a ação de uso das tecnologias como prática técnica que serve à sociedade, nela se poderão observar as rupturas de sua técnica em função de valores distintos que adota como finalidade social de uma dada intervenção. A recusa simbólica dessas rupturas se expressa, como já dito, na crença por parte dos profissionais de um permanente (a-histórico) altruísmo da medicina em salvar (curar/tratar), base de uma técnica que seria 'neutra' por referência a mudanças de valores no sentido do 'salvamento'. Na teia de significados simbólicos dessa construção ideológica, tal percepção a-histórica circularmente se reforça pelo fato de que esses profissionais não podem conceber essa historicidade senão examinando, para além do caráter técnico, o caráter social de suas ações. Assim, essa reconstrução conceitual é uma importante atribuição da História, que deverá apontar para as diferenças entre uma história e ainda uma memória das tecnologias como os meios de intervenção, e a historicidade da prática em medicina em que esses meios comparecem e para a qual são efetivamente criados, nos distintos momentos da vida social.

Os estudos de base sociológica que formularam elementos nesse sentido produziram deslocamentos da compreensão da prática médica como decorrente apenas da expertise de seus agentes, isto é, dessa prática como derivada da posse de saberes científicos e técnicos por parte dos profissionais, inserindo-a em contextos sociais como o mercado de trabalho e as condições de trabalho dadas pelas organizações concretamente possíveis para as instituições prestadoras de serviços no mercado de oferta e consumo de sociedades capitalistas. Também provocaram deslocamentos na tomada do objeto de intervenção da medicina - o corpo. Turner ${ }^{14}$ aponta para o movimento histórico realizado por uma sociologia da saúde que abraça diferentes objetos de estudo, o que é trabalhado por Nunes ${ }^{15}$ da perspectiva da produção latino-americana.

$\mathrm{Na}$ produção bibliográfica sobre a profissão médica, essa Sociologia da Saúde nasce, em boa medida, articulada aos estudos realizados por Freidson ${ }^{16,17}$ nos anos 1970, quando consolida a concepção da profissão em medicina como uma profissão de mercado. De outro lado, como afirmava Donnangelo e Pereira ${ }^{11}$, se o contexto institucional caracteriza as condições de realização das práticas profissionais como trabalho social, outro aspecto fundamental - e que torna tais práticas uma reprodução do social - diz respeito a seu objeto de intervenção: o modo como se consolida, a partir da Modernidade, o conceito de doença e a tomada do corpo como alvo das práticas profissionais. Nesse sentido, o exame das rupturas históricas tem papel central.

Com a formação dos Estados nacionais e a necessidade de constituir e reparar os exércitos que protegem as nações formadas, somadas ao fato histórico da emergência da produção fabril das indústrias e a necessidade de grandes contingentes de trabalhadores manuais, a medicina passa a responder pela necessidade de pronta reparação desses indivíduos e, sobretudo, de modo urgente, pela recuperação da força física de seu corpo. Essa atribuição acaba por exigir conhecimentos e práticas de cura muito voltados para o corpo orgânico e seu bom funcionamento laboral ${ }^{16,18}$. E cabe lembrar que, se é esse o estatuto de caso patológico para a medicina - na já bem discutida manobra da transformação conceitual de caso de doente para caso de doença $^{19}$-, é também sobre essa mesma construção de doença que se apoiam as intervenções da Saúde Pública, ainda quando contabiliza os casos em agrupamentos populacionais.

Podemos ver o reflexo dessa atribuição da prática médica nos adoecimentos e na recuperação de doentes com diferentes ocupações e estatutos na sociedade, atualmente. Tomemos, para ilustrar, a perda do uso da mão por uma fratura traumática que pode resultar em algumas sequelas. Essa situação representa adoecimentos certamente bastante diversos para indivíduos com distintas competências cotidianas: um pianista, 
um trabalhador da indústria têxtil, um cantor, um professor, e assim por diante.

É inegável que os diferentes sentidos do adoecer para cada um desses indivíduos têm implicações no êxito assistencial da intervenção médica, mesmo que a prática, do ponto de vista técnicocientífico, se ampare numa mesma base de conhecimento sobre a patologia - nesse caso, a lesão traumática da mão. Assim, afirmamos, com base em Boltansky ${ }^{20}$, que para indivíduos de posições sociais diferentes o corpo tem diferentes usos sociais, o que repercutirá na prática médica, mesmo que, para a medicina como conhecimento biomédico, o corpo seja um organismo de regularidades comuns aos diferentes indivíduos - o que reforça, para seus profissionais, a ideia da neutralidade de suas práticas, agora especificamente em torno de seu objeto de intervenção, o corpo ${ }^{8}$.

Quer relativamente ao sentido do adoecer e do curar, quer relativamente às condições do exercício profissional, a História surge, também, como disciplina científica que produz conhecimentos sobre a vida social e que pode contribuir para levar aos profissionais da saúde os conhecimentos acerca dessa face social de sua prática. Isso lhes permitirá lidar melhor com a complexidade técnico-social de suas atribuições.

\section{O corpo e o cuidado: uma narrativa histórica possível}

É com Andrea Vesalius, no século XVI, que têm início um processo rápido e profundo de individualização do corpo e sua compreensão de que ele não é isolável do homem ou do mundo: ele é o homem e é, na devida proporção, o cosmos ${ }^{21}$, tanto de sua anatomização quanto de seu desaparecimento, singularidade que intensifica a solidão: solidão dos doentes, solidão dos operados, dos moribundos, daqueles a quem de ora em diante compete decidir sobre a sorte de um corpo que não se assemelha a nenhum outro ${ }^{22}$. Esse aparente paradoxo entre o que deve ser conhecido e o que deve ser silenciado será, sem dúvida, a mais complexa teia a envolver o homem e seu mundo na modernidade.

O normal estará no silêncio corporal, em sua presença-ausência, como diz Le Breton ${ }^{21}$, resultando no corpo que envelhece ou deve envelhecer sob o próprio desconhecimento coletivo. O homem saudável é aquele capaz de suprimir as vozes que podem indicar sua presença anormal. $\mathrm{O}$ que ele deve ter e comunicar é um modelo preestabelecido de posturas, gestos e ações já identificados e modelados por uma natureza saudável ${ }^{21}$.
Nas palavras de Canguilhem, a saúde é a vida em silêncio dos órgãos e, por conseguinte, o normal biológico só é revelado pelas infrações à norma, e só há consciência concreta ou científica da vida por obra da enfermidade ${ }^{19}$. Essa padronização da existência humana levará ao quase desaparecimento do corpo da cena social: este passe de mágica se materializa, à primeira vista, apenas como uma espécie de rejeição ritual das manifestações do corpo - recusa bem característica desse primeiro tipo de corporalidade. Já o patológico fala do corpo que fala, do corpo que cheira, do corpo que emite sons e se apresenta, mesmo que sem ser convidado, à vida social. Diante de um rumor estomacal, de um flato, de uma eructação e mesmo diante de uma lágrima [...] é preciso mentir e dar a impressão de que nada se ouviu, cheirou, enxergou. Em algumas dessas situações, talvez até mesmo risos compareçam - mas esse deslize da norma de fingimento $e$ discrição ocorrerá em geral para expressar a vontade impiedosa de humilhar aquele que não conseguiu se conter nos limites do seu corpo ${ }^{22}$.

O corpo doente é o símbolo do desequilíbrio desse modo de andar a vida, e seu sofrimento, inscrito historicamente, pode tanto repugnar quanto seduzir, gerar modos de assistência, sentimentos de compaixão ${ }^{23}$. Regido pela concepção de progresso da medicina e tornado anormal o permanecer doente ${ }^{24}$, paradoxalmente, o corpo que se apresenta em seu estado patológico, de um lado, exige esforço econômico, político e científico para seu conhecimento e sua intervenção e, de outro, rende lucros - não só para a recuperação de seu valor como peça ativa do sistema capitalista, mas também em sua "constância patológica", no agravamento desta e, no limite, em sua própria morte.

Entre as experiências desse corpo, o adoecimento é um "acontecimento" em que se rompe a concepção de uma permanência histórica do vivido, uma ruptura evidente que faz surgir a singularidade, ao imponderável da História, remetendo à primeira ameaça da experiência histórica humana, quando o corpo luta, em sua representação, por ser ainda um significado no jogo social, no esforço de não cair no cadafalso de seu apagamento paulatino, transformando-se numa potência da memória. Para isso, quando se trata do sofrimento e da expressão de dor, é preciso não acreditar de antemão que é o excesso que se visita, logo, o extraordinário, o histérico, esse dejeto inevitável de toda dificuldade social. Os instantes em que se exprime - de tantas maneiras - a dor revelam a formidável tensão que faz com que se confrontem a ordem e sua negação, a violência e o sentimento vitimário, o ódio e o desejo ${ }^{23}$. 
Nesse sentido, o chamado cuidado médico e em saúde pode ser responsável por essa articulação, na busca de conservar naquele que sofre pelo adoecimento sua potencialidade de sujeito histórico, mesmo que sua experiência histórica corporal dê sinais de que um acontecimento lhe roubou essa esperança da modernidade, que é permanecer sempre numa linha progressiva e estável da vida humana. Segundo José Ricardo Ayres, a estrutura própria do fazer em saúde também se reconstrói quando o norte é a humanização. Por isso, irá se denominar cuidado essa conformação humanizada do ato assistencial, distinguindo-a daquelas que, por razões diversas, não visam essa ampliação e flexibilização normativa na aplicação terapêutica das tecnociências da saúde. Assim, embora a categoria, Cuidado, na filosofia heideggeriana, não diga respeito a cuidar e descuidar no sentido operativo do senso comum e ainda menos numa perspectiva estritamente médica, adota-se aqui o termo cuidado como designação de uma atenção à saúde imediatamente interessada no sentido existencial da experiência do adoecimento físico ou mental, $e$, por conseguinte, também das práticas de promoção, proteção ou recuperação da saúde ${ }^{1}$.

Como aponta o autor, entendido em sua complexidade funcional e subjetiva, $o$ ato de cuidar desse corpo que sofre é a ação dessa desestabilização movendo-se no sentido da ruptura das experiências de quem cuida e de quem é cuidado. Não se reduzindo à noção das conformidades pelo uso de certas tecnologias, mas incutindo nesse processo o domínio da singularidade ou historicidade da relação pela humanização e pelo cuidado. E podemos encontrar, em certos momentos históricos, pistas que mostram não uma continuidade, mas certa percepção do que seria o "mais humano" para esse momento e, por isso, comprovação inequívoca de que o futuro não pode ser mensurado. Para o homem e sua experiência corporal, só o presente em sua historicidade tem sentido.

Entre os lugares em que se pode exercer o cuidado médico e em saúde, o hospital se tornou, na modernidade, o espaço terapêutico tout court de intervenção sobre o doente e a doença, e o médico, o responsável por sua administração, compondo uma grande equipe, hierarquizada e verificável no cotidiano, por exemplo, no ritual da visita, desfile quase religioso em que o médico, na frente, vai ao leito de cada doente seguido de toda a hierarquia do hospital: assistentes, alunos, enfermeiras etc. ${ }^{5}$. Tal forma de organização do trabalho coletivo pode ser entendida pela cooperação dentro de uma divisão técnica do trabalho. Além do que, esses distintos profissionais estão colocados de modo igual diante de uma mesma forma geral de proceder, visto que promovem a reorganização da prática hospitalar com base em procedimentos uniformes nesta: a intervenção terapêutica individual com base na observação coletiva dos casos, no registro sistemático de dados, no estudo individual e comparativo dos casos, no estudo do meio e na intervenção dele ${ }^{7,8}$.

Por isso, é imperativo perscrutar nesses espaços as entrelinhas da experiência humana num certo presente, procurar vestígios relegados por uma versão oficial, buscando a história em seu contrapelo, como disse Walter Benjamin, para fazer falarem os grupos que não deveriam ter voz e para criticar um sentido da história, uma concepção de progresso inevitável ${ }^{25}$, já que o produto da ciência histórica se esconde nas fímbrias dos tempos, dos gestos e das atitudes insuspeitas como o corpo oficialmente silenciado, medicalizado e controlado. Olhar pelas entrelinhas dos documentos, pela história do implícito, será sempre uma estratégia do ofício do historiador na busca de vozes nem sempre divulgadas, mas que continuam como grãos de memória, exatamente pela falta de fonte. Indicação mais que substancial para dizer "eu existo".

Se há silêncios, não necessariamente há esquecimentos ${ }^{26}$, pois sobre a história pesarão sempre rastros de memória, restabelecendo, mesmo em seus limites, o contato entre aquilo que pode ter sido e aquilo que vai sendo, entre aquilo que pode ter se dado de fato e o que nem sempre passará de aparência do depois. É um silêncio que fala: a história pode ampliar, completar, corrigir e até mesmo refutar o testemunho da memória sobre o passado, mas não pode aboli-lo ${ }^{27}$.

Se a lógica da história é constituída por diversas temporalidades, rupturas e permanências fazem parte desse mesmo construto, originando o novo e preservando certas estruturas que, mesmo modificadas, ainda resistem a desaparecer. Nesse contexto, o corpo se representa pelo finito da história, num tempo de curta duração, mas que não deixa de imprimir nele marcas do mundo vivido. Esse corpo é o receptáculo de memórias inscritas, e por ele o tempo escoa rapidamente. Como o corpo definidamente doente deve ser normatizado pelo campo hospitalar, médico e de saúde? E como tal processo é possível ou limitado pelas conjunturas históricas? Se essas são indagações já bastante conhecidas pelos analistas, retomá-las nada mais é que a necessidade premente de pensá-las em quadros ainda desconhecidos, no esforço incessante de dar voz ao aparente silêncio de determinados sujeitos da história. 


\section{Colaboradores}

A Mota e LB Schraiber participaram igualmente de todas as etapas de elaboração do artigo.

\section{Referências}

1. Ayres JRCM. Cuidado: trabalho e interação nas práticas de saúde. Rio de Janeiro: CEPESC, IMS, UERJ, Abrasco; 2009.

2. Hochman G, Santos PX, Pires-Alves F. História, saúde e recursos humanos: análises e perspectivas. Observatório de Recursos Humanos em Saúde no Brasil: estudos e análises 2004; 2:37-50.

3. Braudel F. História e ciências sociais: a longa duração. In: Novais FA, Silva RF, organizadores. Nova história em perspectiva. São Paulo: CosacNaif; 2011.

4. Ginzburg C. Mitos, emblemas e sinais: morfologia e história. São Paulo: Companhia das Letras; 1989.

5. Foucault M. Microfísica do poder. Rio de Janeiro: Graal; 1984.

6. Luz MT. Natural, racional, social: razão médica e racionalidade científica moderna. Rio de Janeiro: Campus; 1988.

7. Schraiber LB. O médico e suas interações: a crise dos vínculos de confiança. São Paulo: Hucitec; 2008.

8. Schraiber LB. Racionalidade biomédica e transformações históricas da prática médica ao longo do século XX: breves apontamentos para a reflexão crítica. In: Pinheiro R, Silva Junior AG, organizadores. Projeto Integralidade em Saúde - 10 anos: por uma sociedade cuidadora 2010; 1:115-128.

9. Cyrino AP. Entre a ciência e a experiência: uma cartografia do autocuidado no diabetes. São Paulo: UNESP; 2009 .

10. Schraiber LB. Quando o "êxito técnico" se recobre de "sucesso prático": o sujeito e os valores no agir profissional em saúde. Cien Saude Colet 2011; 16(7):3041-3042.

11. Donnangelo MCF, Pereira L. Saúde e sociedade. São Paulo: Hucitec; 2011

12. Mota A. Tropeços da medicina bandeirante: medicina paulista (1892-1920). São Paulo: EDUSP; 2005.

13. Conti L. Estrutura social y medicina. In: Aloisi M, Berlinguer G, ContI L, Massuco-Costa A, Misiti R, Mondella F, Omodeo P, Piersanti F, Sepplli T, Somenzi V, Vegetti M, organizadores. Medicina y Sociedad. Barcelona: Fontanela; 1972. p. 287-310.

14. Turner BS. Medical Power and Social Knowledge. London: Sage; 1995.

15. Nunes ED. As ciências sociais em saúde no Brasil e na América Latina. In: Spínola AWP, Castro-Sá EN, Westphal MF, Adorno RCF, Zioni F, coordenadores. Pesquisa social em saúde. São Paulo: Cortez; 1992. p. 25-44.

16. Freidson E. Profession of Medicine: A Study of the Sociology of Applied Knowledge. New York: Dodd, Mead and Company Inc.; 1970.

17. Freidson E. Professional Dominance: The Social Structure of Medical Care. New York: Atherton Press Inc.; 1970.

18. Foucault M. O nascimento da clínica. Rio de Janeiro: Forense-Universitária; 1977.

19. Canguilhem G. O normal e o patológico. Rio de Janeiro: Forense-Universitária; 1982.

20. Boltanski L. As classes sociais e o corpo. Rio de Janeiro: Graal; 1984.

21. Le Breton D. Antropologia do corpo e a modernidade. Rio de Janeiro: Vozes; 2011. 
22. Moulin AM. O corpo diante da medicina. In: Courtine J-J, editor. História do corpo. Petrópolis: Vozes; 2008.

23. Farge A. Lugares para a história. Belo Horizonte: Autêntica; 2011

24. Ferro M. As sociedades doentes do progresso. Lisboa: Instituto Piaget; 2011.

25. Löwy M. Walter Benjamin: aviso de incêndio - uma leitura das teses "Sobre o conceito de história". São Paulo: Boitempo; 2005.

26. Dosse F. A história. Bauru: EDUSC; 2003.

27. Ricoeur P. A memória, a história, o esquecimento. Campinas: Ed. Unicamp; 2007.

Artigo apresentado em 12/09/2013

Aprovado em 18/12/2013

Versão final apresentada em 09/01/2014 